\title{
The Role of Electronic Human Resource Management in Contemporary Human Resource Management
}

\author{
Li Ma, Maolin Ye \\ School of Management, Jinan University, Guangzhou, China \\ Email: Mary5566123@126.com
}

Received 2 March 2015; accepted 3 April 2015; published 7 April 2015

Copyright $@ 2015$ by authors and Scientific Research Publishing Inc.

This work is licensed under the Creative Commons Attribution International License (CC BY). http://creativecommons.org/licenses/by/4.0/

c) (i) Open Access

\begin{abstract}
More and more organizations have been replacing face-to-face human resource management activities with electronic human resource management, E-HRM for short. E-HRM facilitates the HR function to create dynamic and operational capabilities and contributes greatly on HRM effectiveness. This article elaborates on E-HRM in detail on the following aspects: Introduction of E-HRM, types of E-HRM, role of E-HRM, factors influencing utility, effectiveness of E-HRM, determinants of attitude towards E-HRM and the context for E-HRM in China, and it is expected to help people understand E-HRM more comprehensively and systematically.
\end{abstract}

\section{Keywords}

Human Resource, Electronic Human Resource Management E-HRM in China

\section{Introduction}

Great changes have been brought to our economy, society, and culture with the rapid development of science and technology, especially the usage of Internet and computer technology. Over the last few years, with the appearance of these technologies, a new wave of human resource (HR) technology known as electronic human resource management (E-HRM) has emerged (Hooi, 2006) [1].

The term E-HRM was coined in the 1990s and refers to conducting HRM activities with the use of the Internet or the Intranet (Lengnick-Hall \& Moritz, 2003) [2]. Strohmeier (2007) defines E-HRM as the application of information technology for networking and supporting at least two individual or collective actors in their shared performing of HRM activities [3]. The introduction of E-HRM is expected to facilitate a more efficient and stra- 
tegic way of working for HR professionals (Shrivastava \& Shaw, 2003) [4] for the reason that electronic human resource management (E-HRM) provides human resource (HR) functions with the opportunity to create new avenues for contributing to organizational success.

The present paper elaborates on electronic human resource management (E-HRM) in detail on the following aspects, namely definition of E-HRM, types of E-HRM, factors influencing utility, effectiveness of E-HRM, determinants of attitude towards E-HRM and the context for E-HRM in China. Hopefully, this paper could help readers understand E-HRM more comprehensively and sysmematically.

\section{Types of E-HRM}

There are three types of E-HRM. These are described respectively as Operational, Relational and Transformational.

Operational E-HRM is related with administrative functions-payroll and employee personal data for instance. Operational type of HRM provides the choice between asking employees to keep their own personal data up to date through an HR website or to have an administrative force in place to do this.

Relational E-HRM is related with supporting business processes by ways of training, recruitment, performance management and so forth. As to relational HRM, there is the choice between supporting recruitment and selection through a web-based application or using a paper-based approach (through advertisements, paperbased application forms and letters etc.).

Transformational E-HRM is related with strategic HR activities known as knowledge management, strategic re-orientation. As to transformational HRM, it is possible to create a change-ready workforce through an integrated set of web-based tools that enables the workforce to develop in line with the company's strategic choices or to have paper-based materials.

\section{Role of E-HRM}

Classical human resources management (HRM) includes the recruitment, selection, development, compensation, retention, evaluation, and promotion of personnel within an organization (Bernardin \& Russel, 1993), which could be mostly transferred to the virtual world [5]. Therefore, the HR profession faces an important challenge with new E-HRM and virtual actions encountered in the business world. However, E-HRM has been known as its position as the dynamic version of HRM. E-HRM functions share similarities with HR management functions, which are planning for organizations and jobs for people, acquiring human resources, building individual and organizational performance, rewarding employees, maintaining human resources (Fisher, Schoenfeldt, \& Shaw, 1996) [6]. Using E-HRM technology is a way of implementing HR strategies, policies, and practices. The E-HRM technology supports the HR function to abide by the HR needs of the organization based on the network (Ruel et al., 2004) [7]. The E-HRM technology provides a portal which enables managers, employees, and HR professionals to view, extract, or alter information which is necessary for managing the HR of the organization. Additionally, with the use of E-HRM, fewer HR professionals are needed since E-HRM eliminates the "HR middleman".

HR executives are counting on technology and the information it provides to help them drive decisions that will lead to success of the organization as a whole. Snell, Stueber, and Lepak (2002) note that HR can be more strategic, flexible, cost-effective applied with the E-HRM practice [8]. It has been pointed out that IT has the potential to reduce administrative costs, increase productivity, speed response times, enhance decision-making, and improve customer service all at the same time. The need for cost reduction, higher quality services, and cultural change are the three main forces that drive corporations to seek IT-driven HR solutions (Yeung \& Brockbank, 1995) [9]. The rapid development of the Internet during the last decade has boosted the implementation and application of electronic human resource management (Strohmeier, 2007) [3]. According to Strohmeier (2007), E-HRM is the application of information technology for both networking and supporting at least two individual or collective actors in their shared performing of HR activities [3]. Virtual HR is emerging owing to the growing sophistication of IT and increased external structural options (Lepak \& Snell, 1998) [10]. Surveys of HR consultants suggest that both the number of organizations adopting E-HRM and the depth of applications within the organizations are continually increasing. IT is beginning to facilitate firms to deliver great HR services. Many experts forecast that the personal forecast will become the main tool for all HR professionals (Kovach \& Cathcart, 1999) [11]. 
HRM helps to achieve higher performance through the rapid development of technological innovation. Technology innovation could serve as an approach to enable HR function to focus more on value-added activities so as to realize the full potential of technology and organizational strategy (Shrivastava et al., 2003) [4]. The biggest benefit of applying E-HRM practice is the freeing of HR staff from intermediary roles so that they can focus on strategic planning in human resource organization and development (Pinsonneault \& Kraemer, 1993) [12].

\section{Factors Influencing Utility, Effectiveness of E-HRM}

E-HRM has been studied increasingly by many scholars. However,Academic involvement in E-HRM started relatively late and, to an extent, is still trying to catch up with practice (Ruel et al., 2007) [13]. Previous studies on E-HRM have been conducted by various researchers.

Laumer et al. (2010) studied E-HRM in an E-Business environment among 144 HR managers from German top 1000 corpotations. Their survey results revealed that HR managers' most pressing challenges are staff retention and internal and external employer branding. They concluded the importance for an E-HRM that needs to be both effective-adequately fill vacancies-and efficient-make full use of rare resource [14].

Strohmeier and Kabst (2009) examined the factors that affect the cross-national organizational adoption of E-HRM in Europe. They found that E-HRM is a common practice throughout Europe since two-thirds of all organizations have already applied E-HRM. They also found that major determinants of E-HRM adoption are size, work organization, and configuration of HRM [15].

Voermans and van Veldhoven (2007) made a study on attitude towards E-HRM. They found that differences in perceived usability of current IT systems, and the preferred HR roles strategic partner (high preference) and employee champion (low preference), were connected to a positive attitude towards E-HRM systems. As for managers, user support was also considered to be a predictor of a positive attitude towards E-HRM [16].

Olivas-Lujan et al. (2007) conducted a case-based study to investigate how four of the most competitive Mexican firms are applying their E-HRM strategy. They discovered that to fully understand the way E-HRM is used in firms from emerging economies, it is critical to take into account local idiosyncrasies [17].

Ruel et al. (2007) examined the contribution of E-HRM to HRM effectiveness [13]. They found that individual assessment of E-HRM applications affects HRM technical and strategic effectiveness. This is especially so in the perceived quality of the content and the structure of E-HRM applications which have a significant and positive effect on technical and strategic HRM effectiveness. They also discovered that the basic expectations are that using E-HRM will reduce costs, will enhance the HR service level and will supply the HR department space to become a strategic partner.

Hooi (2006) studied the degree of E-HRM practiced in the small and medium sized manufacturing companies. The readiness and feasibility of implementing E-HRM in the SMEs is dependent on the availability of resources (expertise, financial, and technical resources) and the attitude of the employees [1].

Ruel et al. (2004) conducted an explorative empirical study in five large companies on web-based HRM. They concluded that the goals of E-HRM are mainly to improve HR's administrative efficiency/to achieve cost reduction. They also found that international companies seem to use the introduction of E-HRM to standardize HR policies and processes [7].

According to the current studies combined with the academic literature above, we conclude the following factors have great effect on attitude towards using E-HRM: clarity of E-HRM goals, user satisfaction with EHRM, perceived usefulness, perceived ease of use, intention to use E-HRM, user support, social influence, and facilitating condition. These are the important factors connected with attitude of the HR professionals towards using E-HRM. This information is vital when designing implementation methodologies and change management strategies as interventions need to be designed specially to meet the company's requirement of E-HRM implementation. Generally, findings of the present study add to previous work on E-HRM adoption by clearly addressing factors that systematically separate adopting and non-adoption organizations in a cross-national surrounding. Accepting that E-HRM obviously is not a strictly universal practice, it is appropriate for a certain type of organizations while inappropriate for other organizations. The above findings thus contribute to our understanding of the basic technology factors of E-HRM.

\section{Determinants of Attitude towards E-HRM}

Attitude is depicted to be individual's positive or negative behavior towards a new idea or new technology and 
has been known to be a driver of consumer utility or technology adoption (Fishbein \& Ajzen, 1975) [18]. As shown in empirical studies related to the diffusion of technological innovations, attitude exposes one's belief about the evaluation and consequences of a given behavior $(\mathrm{Li}, 2004)$ [19].

\subsection{Clarity of E-HRM Goals}

There is a positive relationship between clarity of E-HRM goals and attitude towards E-HRM. The goals for applying E-HRM technology of a specific organization have an effect on the use of the technology. It is therefore of great importance that the goals are explained right by the end-users otherwise it might result in unintended use of the technology. Ruel (2001) elaborates on the clarity of spirit of office technology. The spirit of the technology should lead to the right user behavior of end-users of the technology [20].

It is recommended by Fishbein that e-business and systems' developers should concentrate on improving user preference by improving technology effectiveness and accessibility through educating the consumers, promoting simple format, efficiency, authenticity, and clarity of web site content [18].

\subsection{User Satisfaction with E-HRM}

There is a positive relationship between user satisfaction and attitude towards E-HRM. User satisfaction is a subjective evaluation of the various uses of experiences of an information system based on a pleasant/unpleasant continuance (Seddon, 1997) [21]. There are extensive literatures on end-user satisfaction with Information Technology. A meta-analysis approach is used by Mahmood (2000) to synthesize and validate the construct of IT end-user satisfaction. It is widely accepted that satisfaction with IT as an indicator of IT usage which is viewed as a vital driver of IT success [22].

Zeithaml, Berry and Parasuraman emphasized that high satisfaction (as perceived by the customer) often result in favorable behavioral intentions while low satisfaction leads to unfavorable behavioral intentions [23]. Many research studies on technology adoption have also proved that user satisfaction has a positive influence upon intention. Carlson and O'Cass found that customer's evaluations of satisfaction with a web site have a significant positive influence on attitudes towards the web site in an empirical research from an online survey of 518 customers [24].

\subsection{Perceived Usefulness and Perceived Ease of Use}

There is a positive relationship between perceived usefulness, perceived ease of use and attitude towards E-HRM. Studies have demonstrated that ease of use and usefulness were linked with attitude toward using technology.

Perceived Usefulness is of great importance as to the acceptance of E-HRM technology by organizations. HR professionals are always interested in how E-HRM technology enhances the workplace especially in HR function as to costs reduction, time management, and task execution. Perceived usefulness is one of the Technology Acceptance Model primary core determinants for computer acceptance behavior and its importance has been acknowledged in technology adoption (Agarwal \& Prasad, 1997) [25]. Lots of existing evidences to support the positive effect of perceived usefulness on the adoption of technologies (Venkatesh \& Davis, 2000) [26].

Perceived Ease of Use reflects the extent of difficulty in understanding, learning, or applying the technology. It also reflects the extent to which a new technology is perceived as better than the substitutes. In this context, the HR professional's perception that using E-HRM will include minimum effort or that E-HRM will be easy to deal with, is an important factor in E-HRM adoption. Based on Technology Acceptance Model, perceived ease of use leads to intention which in turn generates the actual individual usage behavior.

\subsection{User Support}

There is a positive relationship between user support and attitude towards E-HRM. User Support addresses the technical support and help given to users in the light of operating the information systems in the organization. The importance of user support to the success of user computing has been emphasized in many researches (Amoroso and Cheney, 1991; Igbaria et al. 1997) [27] [28]. In the working context, we hold that technical support to users of the E-HRM system is critical.

Studies have shown that an individual's attitude is affected by various constructs or external variables, which 
may be system features, training, documentation, and user support. Therefore, user support is sure to influence the attitude towards E-HRM.

\subsection{Social Influence}

There is a positive relationship between social influence and attitude towards E-HRM. Venkatesh et al. (2003) define Social Influence as "the extent to which an individual perceives that important others believe he or she should use the new system” (p. 451) [29]. According to the researcher, the use of the E-HRM technology had not been mandated by the management of the organizations under study.

Previous studies demonstrated that Social influence has been an important factor that affects individuals' attitudes and intentions toward a certain behavior. For example, Chan et al. indicated that the effect of social influence may have a positive impact on attitude (user satisfaction) while this relationship was not significant in their study on mandatory citizen adoption of an e-government technology. Karjaluoto argued social influence strongly affected attitude and behavior toward online banking [30].

\subsection{Facilitating Conditions}

There is a positive relationship between facilitating conditions and attitude towards E-HRM. Venkatesh et al. (2003) describe Facilitating Conditions as "the extent to which an individual thinks that an organizational and technical infrastructure exists to support use of the system” (p. 453) [31]. In the study, the facilitating conditions include the necessary support from the HR and IT department to supply education and assistance to the employees. Moreover, facilitating conditions include the technical infrastructure that offers a highly available and responsive system to the users.

It is theorized that Facilitating conditions often have a direct effect on intention and use of information system. Chan argued that facilitating conditions have a positive impact on user satisfaction; and this relationship was confirmed in their study. Liang, Xue, Ke and Wei demonstrated that the facilitating conditions have significant influences on information technology use [32].

\section{The Context for E-HRM in China}

As to E-HRM in the context of China, research seems to be limited to E-HRM implementation in a local enterprise (Xin, 2010) [32] or E-HRM implementation challenges in a state-owned enterprise (SOE) (Zhang and Wang, 2006) [33]. We must note that there are several features of the Chinese institutional environment that are likely to influence the deployment and utilization of E-HRM in China.

First of all, the Chinese regulatory context for E-HRM-comprising the national laws that promote and limit various behaviors - has undergone huge changes these years (Dezalay and Garth, 2011) [34]. For instance, in 2008, the introduction of new labor laws produced fears that the improvements designed to protect workers from arbitrary firings will increase costs by raising requirements for severance pay (Chen and Funke, 2009) and add the workload for human resource [35]. Additionally, communist hukou system (the registration of households) has influenced HRM practices. This registration is the legal basis for identification, and an individual cannot acquire a legal permanent residence, benefits or privileges in any place other than the registered birthplace (hukou). Corporations have to report hukou data to the authorities (Wang, 2005) [36]. Xue et al. (2005) argue that the most problematic function of E-HRM systems is thus the ability to generate reports that meet both the local government and central government requirements [37].

Secondly, with respect to social knowledge about E-HRM, a strongly hierarchical structure characterizes the cognitive institutional environment. This has been the result of centralized planning and has resulted in a historical absence of the Western HR concept (Björkman et al., 2008) [38]. However, corporate investment in developing local HR managers and increased academic education in HRM seems to be raising the status of human resource management (Cooke, 2004) [39]. Although study shows that HRM in China is not meeting executives’ expectations and is associated with administrative work, longitudinal research offers a more positive view of a growing strategic role, including the progressive application of Western-style HRM practices (Sumelius, 2009) [40]. E-HRM practice application in China is especially challenging due to the lack of well-trained employees, information technology infrastructure, high technical and cultural complexity and differences between Western and Chinese management practices. 
Lastly, core values, beliefs about human nature and norms, the normative institutional environment for EHRM has been emphasized in several studies. Chow (2004) argues tendencies towards the use of networks (guanxi) in staffing practices [42]. Guanxi, a social capital network which is the continual exchange of services and favors within the network (Luo, 2002) is still of great significance [41]. Having the right connections and the good viewpoints of co-workers are considered vital (Chow, 2004), In China, an applicant can easily pass formal screening criteria within companies with the use of guanxi [42]. It seems overall enterprise resource planning use in the Chinese context is being influenced by informal planning and process modeling, which is highly dependent on guanxi, which makes communication barriers between users and demands resources in terms of system modifications (Ge and Voss, 2009; Huang and Palvia, 2001) [43] [44]. Other research showed a preference for sustaining harmonious Confucian-based relationships in how performance appraisals are conducted (Hempel, 2001) [45]. Furthermore, Huo and Von Glinow (1995) suggest that typical Chinese cultural features such as the concept of "face" and respect for authority deciding the desirability of certain HRM practices [46]. That Chinese culture respects seniority and hierarchy, values social harmony, and adopts an egalitarian approach to HR service distribution is noted by Cooke (2013) [47].

China has its unique national conditions and culture, whether E-HRM will succeed in China depends largely on if the corporations focus on China's national conditions and cultural characteristics. To conclude, this literature review demonstrates a need to understand how standardization and adaptation to the local context affect E-HRM in terms of it realizing its strategic potential and the particular institutional forces that are influencing this.

\section{Conclusions}

Human resources are considered as the most expensive resource in any organization; therefore, they need careful management. The goal of human resources management is to make sure that a company has the right number of people with the required knowledge, skills, abilities and competencies, in the right place, at the right time, at an affordable cost and who are motivated and determined to achieving the current and strategic need of a firm. E-HRM practice provides a more efficient and strategic way of working to reach the goals. E-HRM facilitates human resource functions with the chance to create new avenues for committing to organizational success.

Nowadays, a great many technological applications have emerged, claiming to cover nearly every "traditional" human resources management (HRM) activity; not only complementing it, but often even substituting it (Martin, Alexander, Reddington, \& Pate, 2006) [48]. In order to meet the demands of today's knowledge-based economy, it is almost a must for companies to maximize the potential and productivity of their employees, a goal towards which HRM information systems and E-HRM could be of help.

\section{References}

[1] Hooi, L.W. (2006) Implementing e-HRM: The Readiness of Small and Medium Sized Manufacturing Companies in Malaysia. Asia Pacific Business Review, 12, 465-485. http://dx.doi.org/10.1080/13602380600570874

[2] Lengnick-Hall, M.L. and Moritz, S. (2003) The Impact of e-HR on the Human Resource Management Function. Journal of Labor Research, 24, 365-379. http://dx.doi.org/10.1007/s12122-003-1001-6

[3] Strohmeier, S. (2007) Research in e-HRM: Review and Implications. Human Resource Management Review, 17, $19-37$. http://dx.doi.org/10.1016/j.hrmr.2006.11.002

[4] Shrivastava, S. and Shaw, J.B. (2003) Liberating HR through Technology. Human Resource Management, 42, $201-222$. http://dx.doi.org/10.1002/hrm.10081

[5] Bernardin, H.J. and Russell, J.E. (1993) Human Resource Management: An Experiential Approach. McGraw-Hill, New York.

[6] Fisher, C.D., Schoenfeldt, L.F. and Shaw, J.B. (1996) An Introduction to Human Resource Management. Houghton Mifflin Company, Boston.

[7] Ruël, H., Bondarouk, T. and Looise, J.K. (2004) E-HRM: Innovation or Irritation. An Explorative Empirical Study in Five Large Companies on Web-Based HRM. Management Revue, 15, 364-380.

[8] Snell, S.A., Stueber, D. and Lepak, D.P. (2002) Virtual HR Departments: Getting Out of the Middle. CAHRS Working Paper Series, 71. http://digitalcommons.ilr.cornell.edu/cahrswp/71

[9] Yeung, A.K. and Lake, D.G. (1995) Human Resource Competencies: An Empirical Assessment. Human Resource Management, 34, 473-495. http://dx.doi.org/10.1002/hrm.3930340402 
[10] Lepak, D.P. and Snell, S.A. (1998) Virtual HR: Strategic Human Resource Management in the 21st Century. Human resource Management Review, 8, 215-234. http://dx.doi.org/10.1016/S1053-4822(98)90003-1

[11] Kovach, K.A. and Cathcart, C.E. (1999) Human Resource Information Systems (HRIS): Providing Business with Rapid Data Access, Information Exchange and Strategic Advantage. Public Personnel Management, 28, 275-282.

[12] Pinsonneault, A. and Kraemer, K.L. (1993) Survey Research Methodology in Management Information Systems: An Assessment. Journal of Management Information Systems, 10, 75-105.

[13] Ruel, H.J., Bondarouk, T.V. and Van der Velde, M. (2007) The Contribution of E-HRM to HRM Effectiveness: Results from a Quantitative Study in a Dutch Ministry. Employee Relations, 29, 280-291. http://dx.doi.org/10.1108/01425450710741757

[14] Laumer, S., Eckhardt, A. and Weitzel, T. (2010) Electronic Human Resources Management in an E-Business Environment. Journal of Electronic Commerce Research, 11, 240-250.

[15] Strohmeier, S. and Kabst, R. (2009) Organizational Adoption of E-HRM in Europe: An Empirical Exploration of Major Adoption Factors. Journal of Managerial Psychology, 24, 482-501. http://dx.doi.org/10.1108/02683940910974099

[16] Voermans, M. and van Veldhoven, M.J.P.M. (2007) Attitude towards E-HRM: An Empirical Study at Philips. Personnel Review, 36, 887-902. http://dx.doi.org/10.1108/00483480710822418

[17] Olivas-Lujan, M.R., Ramirez, J. and Zapata-Cantu, L. (2007) E-HRM in Mexico: Adapting Innovations for Global Competitiveness. International Journal of Manpower, 28, 418-434. http://dx.doi.org/10.1108/01437720710778402

[18] Fishbein, M. and Ajzen, I. (1975) Belief, Attitude, Intention and Behavior: An Introduction to Theory and Research. Addison-Wesley, Reading.

[19] Li, Q., Zhang, S.M., Chen, H.T., Fang, S.P., Yu, X., Liu, D. and Zeng, F.D. (2004) Awareness and Attitudes of Healthcare Professionals in Wuhan, China to the Reporting of Adverse Drug Reactions. Chinese Medical Journal, 117, 856-861.

[20] Rüel, H.J.M. (2001) The Non-Technical Side of Office Technology: Managing the Clarity of the Spirit and the Appropriation of Office Technology. In: Snodgrass, C.R. and Szewczak, E.J., Eds., Managing the Human Side of Information Technology: Challenges and Solutions, Idea Group Publishing, Hershey, PA, 78-104.

[21] Seddon, K.R. (1997) Ionic Liquids for Clean Technology. Journal of Chemical Technology and Biotechnology, 68, 351-356. http://dx.doi.org/10.1002/(SICI)1097-4660(199704)68:4<351::AID-JCTB613>3.0.CO;2-4

[22] Mahmood, M.A., Burn, J.M., Gemoets, L.A. and Jacquez, C. (2000) Variables Affecting Information Technology End-User Satisfaction: A Meta-Analysis of the Empirical Literature. International Journal of Human-Computer Studies, 52, 751-771. http://dx.doi.org/10.1006/ijhc.1999.0353

[23] Zeithaml, V.A., Berry, L.L. and Parasuraman, A. (1996) The Behavioral Consequences of Service Quality. The Journal of Marketing, 60, 31-46. http://dx.doi.org/10.2307/1251929

[24] Carlson, J. and O’Cass, A. (2010) Exploring the Relationships between E-Service Quality, Satisfaction, Attitudes and Behaviours in Content-Driven E-Service Web Sites. Journal of Services Marketing, 24, 112-127. http://dx.doi.org/10.1108/08876041011031091

[25] Agarwal, R. and Prasad, J. (1997) The Role of Innovation Characteristics and Perceived Voluntariness in the Acceptance of Information Technologies. Decision Sciences, 28, 557-582. http://dx.doi.org/10.1111/j.1540-5915.1997.tb01322.x

[26] Venkatesh, V. and Davis, F.D. (2000) A Theoretical Extension of the Technology Acceptance Model: Four Longitudinal Field Studies. Management Science, 46, 186-204. http://dx.doi.org/10.1287/mnsc.46.2.186.11926

[27] Amoroso, D.L. and Cheney, P.H. (1991) Testing a Causal Model of End-User Application Effectiveness. Journal of Management Information Systems, 8, 63-89.

[28] Igbaria, M., Zinatelli, N., Cragg, P. and Cavaye, A.L. (1997) Personal Computing Acceptance Factors in Small Firms: A Structural Equation Model. MIS Quarterly, 21, 279-305. http://dx.doi.org/10.2307/249498

[29] Venkatesh, V., Morris, M.G., Davis, G.B. and Davis, F.D. (2003) User Acceptance of Information Technology: Toward a Unified View. MIS Quarterly, 27, 425-478.

[30] Karjaluoto, H., Mattila, M. and Pento, T. (2002) Factors Underlying Attitude Formation towards Online Banking in Finland. International Journal of Bank Marketing, 20, 261-272. http://dx.doi.org/10.1108/02652320210446724

[31] Liang, H., Xue, Y., Ke, W. and Wei, K.K. (2010) Understanding the Influence of Team Climate on IT Use. Journal of the Association for Information Systems, 11, 414-432.

[32] Ma, X. (2010) A Framework of E-HRM Information Systems in Fashion Enterprise. Proceedings of the 2010 Second International Conference on Information Technology and Computer Science (ITCS), Kiev, 24-25 July 2010, 305-308.

[33] Zhang, L. and Wang, H. (2006) Intelligent Information Processing in Human Resource Management: An Implementation Case in China. Expert Systems, 23, 356-369. http://dx.doi.org/10.1111/j.1468-0394.2006.00416.x 
[34] Dezalay, Y. and Garth, B., Eds. (2011) Lawyers and the Rule of Law in an Era of Globalization. Routledge, London.

[35] Chen, Y.F. and Funke, M. (2009) China's New Labour Contract Law: No Harm to Employment? China Economic Review, 20, 558-572. http://dx.doi.org/10.1016/j.chieco.2009.03.008

[36] Wang, F.L. (2005) Brewing Tensions While Maintaining Stabilities: The Dual Role of the Hukou System in Contemporary China. Asian Perspective, 29, 85-124.

[37] Xue, Y., Liang, H., Boulton, W.R. and Snyder, C.A. (2005) ERP Implementation Failures in China: Case Studies with Implications for ERP Vendors. International Journal of Production Economics, 97, 279-295. http://dx.doi.org/10.1016/j.ijpe.2004.07.008

[38] Björkman, I., Smale, A., Sumelius, J., Suutari, V. and Lu, Y. (2008) Changes in Institutional Context and MNC Operations in China: Subsidiary HRM Practices in 1996 versus 2006. International Business Review, 17, 146-158. http://dx.doi.org/10.1016/j.ibusrev.2008.02.001

[39] Cooke, F.L. (2004) HRM in China. In: Budhwar, P.S., Ed., Managing Human Resources in Asia-Pacific, Routledge, London, 17-34. http://dx.doi.org/10.4324/9780203643167.ch2

[40] Sumelius, J. (2009) Developing and Integrating HRM Practices in MNC Subsidiaries in China. Hanken School of Economics, Helsinki.

[41] Luo, Y. (2002) Corruption and Organization in Asian Management Systems. Asia Pacific Journal of Management, 19, 405-422. http://dx.doi.org/10.1023/A:1016252021370

[42] Hau-siu Chow, I. (2004) The Impact of Institutional Context on Human Resource Management in Three Chinese Societies. Employee Relations, 26, 626-642. http://dx.doi.org/10.1108/01425450410562218

[43] Ge, L. and Voß, S. (2009) ERP Application in China: An Overview. International Journal of Production Economics, 122, 501-507. http://dx.doi.org/10.1016/j.ijpe.2009.06.009

[44] Huang, Z. and Palvia, P. (2001) ERP Implementation Issues in Advanced and Developing Countries. Business Process Management Journal, 7, 276-284. http://dx.doi.org/10.1108/14637150110392773

[45] Hempel, P.S. (2001) Differences between Chinese and Western Managerial Views of Performance. Personnel Review, 30, 203-226. http://dx.doi.org/10.1108/00483480110694525

[46] Paul Huo, Y. and Von Glinow, M.A. (1995) On Transplanting Human Resource Practices to China: A Culture-Driven Approach. International Journal of Manpower, 16, 3-15. http://dx.doi.org/10.1108/01437729510102657

[47] Cooke, F.L. (2013) Human Resource Management in China: New Trends and Practices. Routledge, London.

[48] Martin, G., Alexander, H., Reddington, M. and Pate, J.M. (2006) Using Technology to Transform the Future of HR: An Illustrated Model of E-HR. Proceedings of the Academy of Management Annual Conference, Atlanta, 11-16 August 2006, 12-16. 